\title{
Characteristics of Corrosion Product Layer Formed on Weathering Steel Exposed to the Tropical Climate of Vietnam
}

\author{
Le Thi Hong Lien, Hoang Lam Hong
}

Institute of Materials Science, Vietnam Academy of Science and Technology, Hanoi, Vietnam.

Email: honglien@ims.vast.ac.vn

Received May $12^{\text {th }}, 2013$; revised June $14^{\text {th }}, 2013$; accepted June $27^{\text {th }}, 2013$

Copyright (C) 2013 Le Thi Hong Lien, Hoang Lam Hong. This is an open access article distributed under the Creative Commons Attribution License, which permits unrestricted use, distribution, and reproduction in any medium, provided the original work is properly cited.

\begin{abstract}
The weathering steel (Corten B) was exposed to out-door atmosphere of Hanoi (urban site) and Donghoi (marine site). The results showed the protective ability of corrosion product layer formed on weathering steel in the initial stage. The SEM-EDX analysis detected the presence of chromium and copper in the inner layers of corrosion product formed on weathering steel. These elements improved corrosion resistance of corrosion product layers. In addition, the dense $\alpha-\mathrm{FeOOH}$ phase were appeared early in corrosion product which is detected by X-ray diffraction and Micro Raman investigations. The results of polarization and EIS measurements also demonstrated the protectiveness of the corrosion product of weathering steel.
\end{abstract}

Keywords: Weathering Steel; Corrosion Product Layer; Protectiveness; Exposed to; Inner Layer; Outer Layer

\section{Introduction}

There are many works studying on protectiveness of rust layer formed on weathering steel (WS) exposed to atmosphere and following results were reported [1-9]. The main phases of rust are different oxy-hydroxides as $\alpha$ $\mathrm{FeOOH}$ (goethite), $\beta$ - $\mathrm{FeOOH}$ (akaganeite) and $\gamma$ - $\mathrm{FeOOH}$ (lepidocrocite), some spinel type of iron oxides such as magnetite $\mathrm{Fe}_{3} \mathrm{O}_{4}$ are contained in the rust layer depending on environmental condition. Among them $\alpha-\mathrm{FeOOH}$ forms a dense packed and uniform layer of nano-sized particles, which are closely attached to the under-laying steel substrate. The corrosion protective ability of WS is mainly attributed to this dense $\alpha$-phase whose formation is stimulated by dry-wet-dry cycling. In addition, the enhanced corrosion resistance of WS is achieved by adding alloying elements in which copper $(\mathrm{Cu})$ has the most pronounced beneficial effect. $\mathrm{Cu}$ may retard anodic dissolution of iron or decrease the electronics conductivity of the rust layer so that the flow rate of electrons reaching the sites for the cathodic reaction is decrease. As with copper, nickel (Ni) can form small amounts of relatively protective hydroxy-sulfates. Like copper hydroxyl-sulfates, they may improve the barrier effect by clogging pores of the corrosion product $(\mathrm{CP})$ layer. Chromium (Cr) results in substitution of iron $(\mathrm{Fe})$ by $\mathrm{Cr}$ in the $\alpha$-phase, so that a densely packed layer of nanosize of $\alpha-\left(\mathrm{Fe}_{1-\mathrm{x}} \mathrm{Cr}_{\mathrm{x}}\right) \mathrm{OOH}$ is formed and mainly contributes to the long term stability of WS [1]. In the early stage of $\mathrm{CP}$ formation $\mathrm{Cr}, \mathrm{P}$ and $\mathrm{Cu}$ have been observed in the layer of CP closest to the substrate.

This paper introduces the results of exposing WS to outdoor atmosphere in very early stage ( 1 - 30 days), the formation and protective characteristics of corrosion product are investigated and discussed.

\section{Experimental Method}

The samples of WS and carbon steel (CS) with size of $100 \times 75 \mathrm{~mm}$ were exposure to urban atmosphere (Hanoi) and to coastal atmosphere (Donghoi), their positions are shown in Figure 1. At Hanoi site the samples were put on the racks faced to the South and at Donghoi site-faced to the sea. The samples were taken off after $1,3,7,14$, 30 days, $3,6,12$ and 24 months.

The corrosion rate (CR) was determined by mass loss of samples after removing $\mathrm{CP}$ according to ISO standard 8407 [10]. 


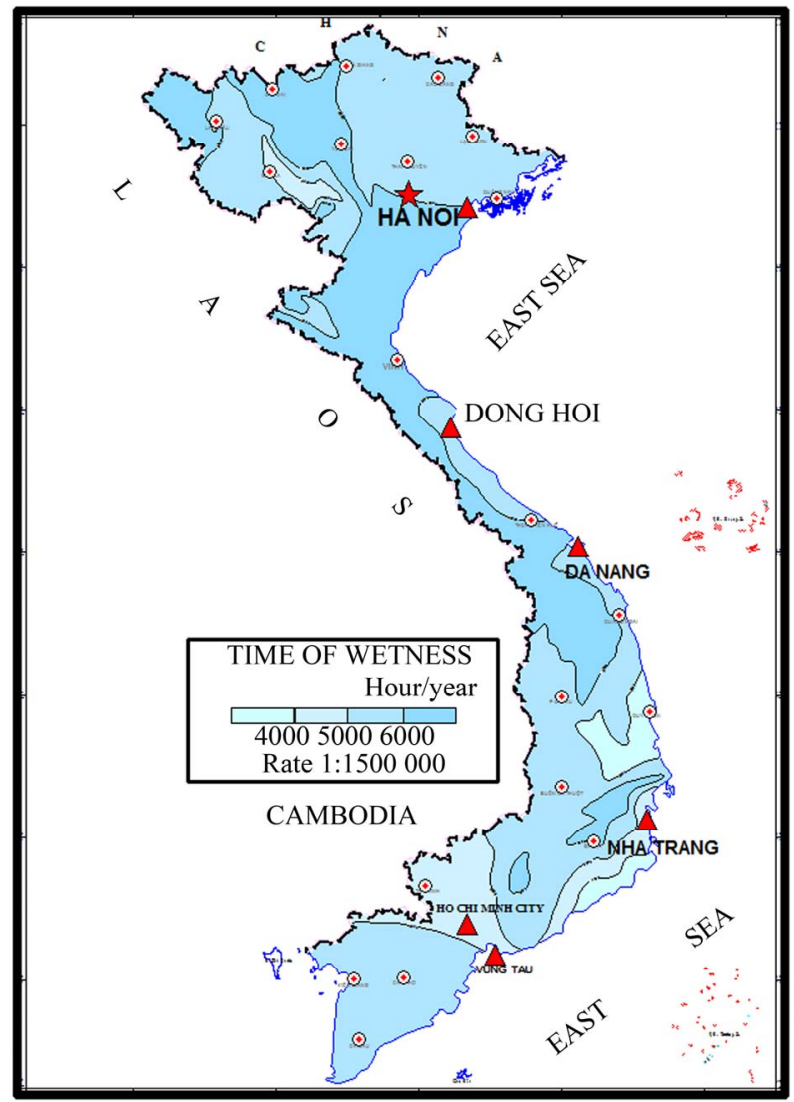

Figure 1. Position of the test sites.

The environmental parameters (Table 1) were collected during exposure time as follows: air temperature (T) and air relative humidity $(\mathrm{RH})$ were obtained at the meteorological stations near by the exposure sites, the chloride deposition rate $\left(\mathrm{Cl}^{-}\right)$was determined by "wet candle" method according to ISO 9225 [11].

The characteristics of corrosion product (rust) formed on WS were investigated using Scanning Electron Microscope (SEM-EDX), X-ray diffraction and MicroRaman techniques as well as measuring polarization curves and Electro-chemical Impedance Scope (EIS).

\section{Results and Discussion}

\subsection{Environmental Characteristics of Test Sites}

As showed in the Figure 1, Hanoi is a big city that is located in the North of Vietnam and about $100 \mathrm{~km}$ far from the sea, whereas Donghoi is a tow in the middle of Vietnam with the exposure site located about $0.3 \mathrm{~km}$ from the sea-shore.

The annual average values of main environmental parameters at the exposure sites are given in Table 1. It can be seen that RH, time of wetness (TOW), total of rain fall (Rf) as well as chloride deposition rate at Donghoi are
Table 1. Environmental parameters of test sites.

\begin{tabular}{cccccc}
\hline Sites & T, ${ }^{\circ} \mathrm{C}$ & $\mathrm{RH}, \%$ & $\mathrm{TOW}, \mathrm{h} / \mathrm{y}$ & $\begin{array}{c}\text { Total of rain } \\
\text { fall, } \mathrm{mm} / \mathrm{y}\end{array}$ & $\mathrm{Cl}^{-}, \mathrm{mg} / \mathrm{m}^{2} \cdot \mathrm{d}$ \\
\hline Hanoi & 24.1 & 79.8 & 4917 & 1585 & 3 \\
Donghoi & 24.8 & 82.58 & 5604 & 2153 & 40 \\
\hline
\end{tabular}

higher than those at Hanoi, these accelerate corrosion process at the beginning. The variation of $\mathrm{T}$ and $\mathrm{RH}$ at test sites in the first month-exposure is shown in Figure 2.

The exposure started in April (end of spring), during this time RH at Donghoi are higher than those at Hanoi, the $\mathrm{Cl}^{-}$deposition rate at Donghoi and Hanoi is 15 and 3 $\mathrm{mg} / \mathrm{m}^{2} \cdot$ day, respectively. When exposure was started $\mathrm{RH}$ values at Donghoi were very high $(>90 \%)$ whereas at Hanoi-a little bit lower (80\% - 90\%).

\subsection{Corrosion Behavior of Weathering Steel}

The initial CR of WS is very high, however it reduces with exposure-time due to the formation of $\mathrm{CP}$ on the sample surface. In first year the CR of WS at Hanoi is similar to that of CS, and then it decreases faster and becomes lower in comparison with CS (Figure 3). The difference is expressed more clearly at Donghoi site where CR of WS is always smaller than that of CS. This can be explained by the faster formation of protective layer contained ion of $\mathrm{Cu}$ and $\mathrm{Cr}$ on WS samples exposed to Donghoi which is perhaps promoted by high humidity as discussed below.

\subsection{Characteristics of Corrosion Products (Rust) on Weathering Steel}

\subsubsection{The Morphology of Rust}

Figures $\mathbf{4}$ and $\mathbf{5}$ show the behavior of sample surface after 1, 3, 7, 14, 30-day-exposure. It can be seen that at Donghoi the rust formed just after fist day as spots distributing on all substrate, while at Hanoi the steel base almost was not corroded. After three days the rust spread out almost surface of samples exposed at Hanoi, but at Donghoi it developed into the bigger spots that characterizes corrosion in environment with chloride. After one month, at both sites the rust completely covered surface of samples.

\subsubsection{The Chemical Element Composition of Rust}

As showed in the literatures [1-9] the corrosion protective ability of WS is mainly attributed to the dense $\alpha$ phase as well as presence of $\mathrm{Cu}$ and $\mathrm{Cr}$ in the rust. Therefore the outer layer of rust was uncovered in order to determine the chemical composition of the inner layer.

The results (Figures 6-8 and Table 2) show the 

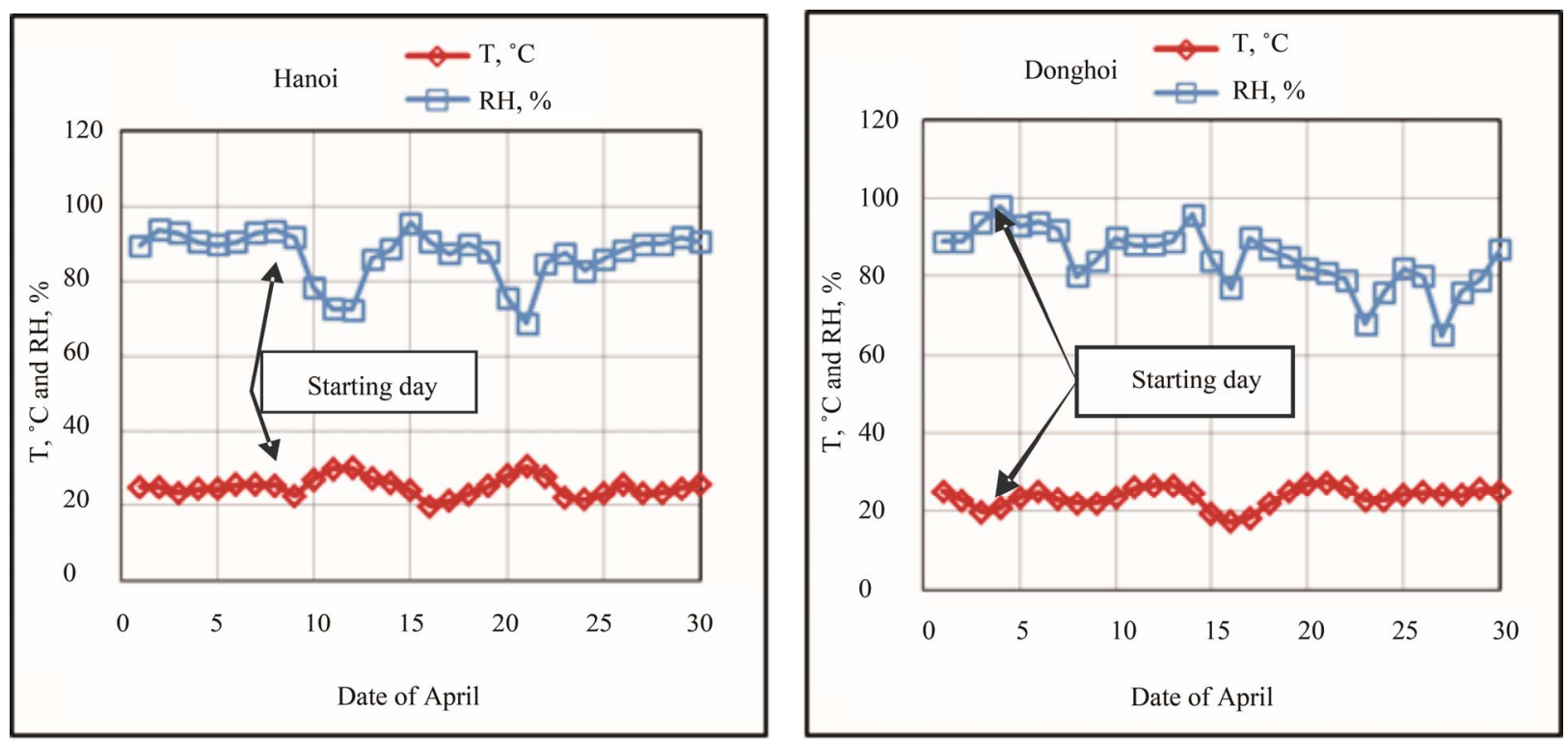

Figure 2. Variation of $\mathrm{T}$ and $\mathrm{RH}$ at test sites in the first month-exposure.
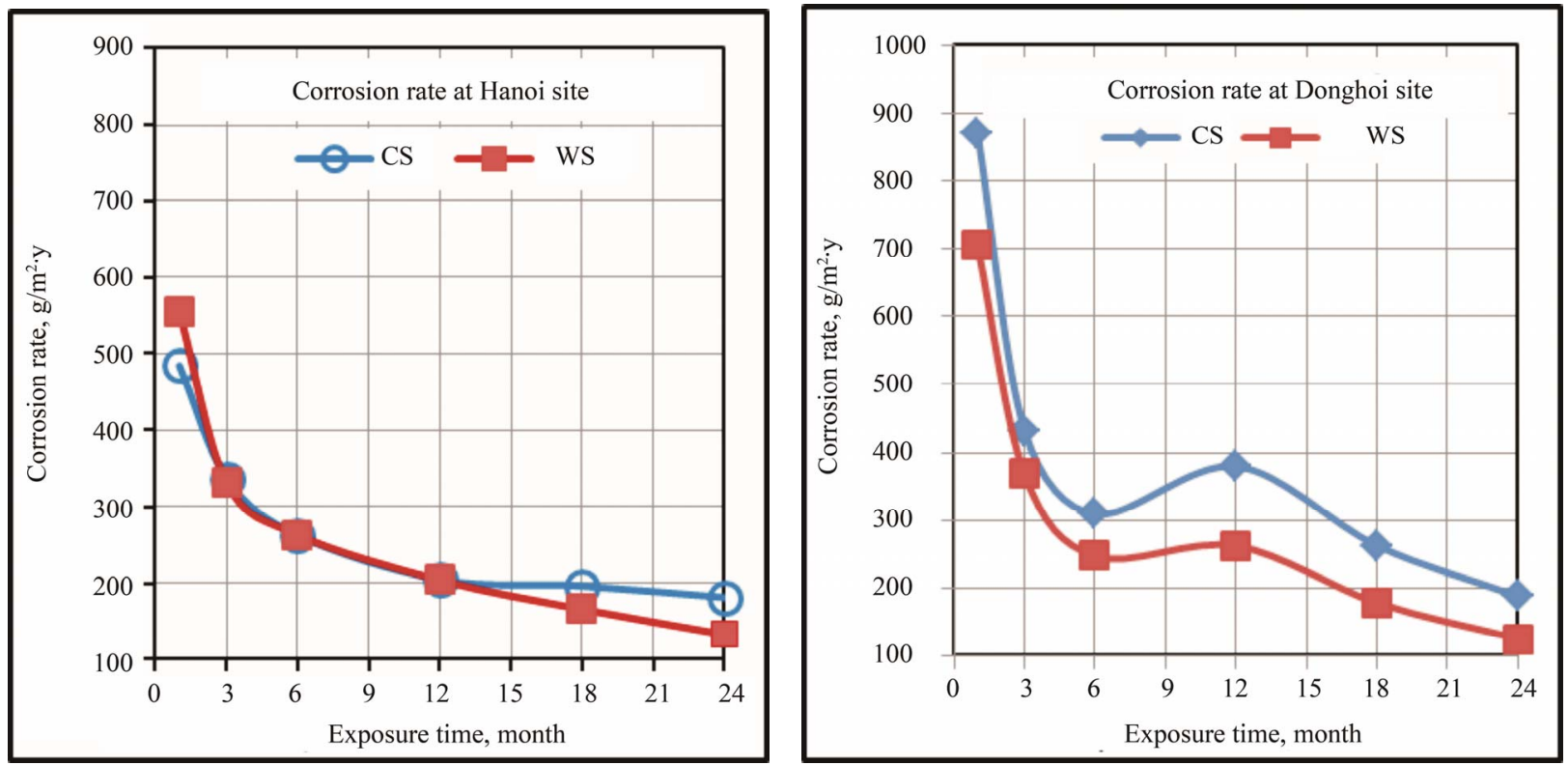

Figure 3. The variation of corrosion with test time.

presence of $\mathrm{Cr}$ and $\mathrm{Cu}$ in the rust; $\mathrm{Cr}$ appeared sooner than $\mathrm{Cu}$ did. Just after first-day-exposure $\mathrm{Cr}$ was detected in the rust formed at both two sites, however it appeared only as traces on the sample exposed to Hanoi (with very low intensity of peak signed by “*” signal), at that time $\mathrm{Cu}$ was present weakly in the rust formed at Donghoi (Figure 6). After three days, $\mathrm{Cr}$ was found clearly in the rust formed at Hanoi (Figure 7), and after 7 day-exposure both $\mathrm{Cr}$ and $\mathrm{Cu}$ appeared clearly in the rust formed at Hanoi as well as Donghoi (Figure 8).

The EDX line scan analysis was performed on the cross-section of rust formed on the sample exposed for one month at Donghoi (Figure 9). It is recognized that $\mathrm{Cr}$ and $\mathrm{Cu}$ existed mainly in the inner layer, especially $\mathrm{Cu}$ was detected only at the positions closest steel substrate. This is confirmed by the results given in the publication [1-9]. Copper is effective to impede the crystallization of $\alpha-\mathrm{FeOOH}$ phase and chromium presumably suppress the formation of $\mathrm{Fe}_{3-\delta} \mathrm{O}_{4}[3,6]$, besides, $\mathrm{Cr}$ results in the substitution of iron by $\mathrm{Cr}$ in the $\alpha$-phase, so that a dense packed layer of nano-size of $\alpha-\left(\mathrm{Fe}_{1-\mathrm{x}} \mathrm{Cr}_{\mathrm{x}}\right)$ $\mathrm{OOH}$ was formed and contributes to the long term stability of WS [1]. It is noticeable that the very high RH at the beginning of exposure perhaps stimulated so early 
Tropical Climate of Vietnam

Table 2. Content of chromium and copper in CP formed on the samples after different exposure periods at Donghoi and Hanoi.

\begin{tabular}{|c|c|c|c|c|}
\hline \multirow[t]{2}{*}{ Exposure time, day } & \multicolumn{2}{|c|}{ Donghoi } & \multicolumn{2}{|c|}{ Hanoi } \\
\hline & $\mathrm{Cr}$ & $\mathrm{Cu}$ & $\mathrm{Cr}$ & $\mathrm{Cu}$ \\
\hline \multirow{4}{*}{1} & 2.12 & $0.89^{*}$ & $0.46^{*}$ & not detected \\
\hline & 1.30 & $0.47^{*}$ & $0.66^{*}$ & not detected \\
\hline & 1.86 & $0.98^{*}$ & $0.51^{*}$ & $0.16^{*}$ \\
\hline & 2.03 & $1.55^{*}$ & $0.25^{*}$ & not detected \\
\hline \multirow{4}{*}{3} & 1.35 & $0.76^{*}$ & 2.10 & $1.15^{*}$ \\
\hline & 1.73 & $1.10^{*}$ & 1.19 & $0.33^{*}$ \\
\hline & 0.91 & $0.23^{*}$ & 1.87 & $1.34^{*}$ \\
\hline & 0.57 & $0.72^{*}$ & 1.43 & $0.54^{*}$ \\
\hline \multirow{5}{*}{7} & $\mathrm{Cr}$ & $\mathrm{Cu}$ & $\mathrm{Cr}$ & $\mathrm{Cu}$ \\
\hline & 2.56 & 3.28 & 3.26 & 2.33 \\
\hline & 1.07 & $0.47^{*}$ & 1.91 & $1.18^{*}$ \\
\hline & 4.29 & 2.88 & 4.65 & 3.18 \\
\hline & & & 1.89 & $0.61^{*}$ \\
\hline \multirow{4}{*}{14} & 1.62 & 1.86 & 2.75 & $1.36^{*}$ \\
\hline & 0.54 & 1.29 & 4.25 & 2.27 \\
\hline & 0.74 & $0.15^{*}$ & 3.33 & 3.61 \\
\hline & 1.97 & 2.34 & 3.31 & 2.91 \\
\hline
\end{tabular}
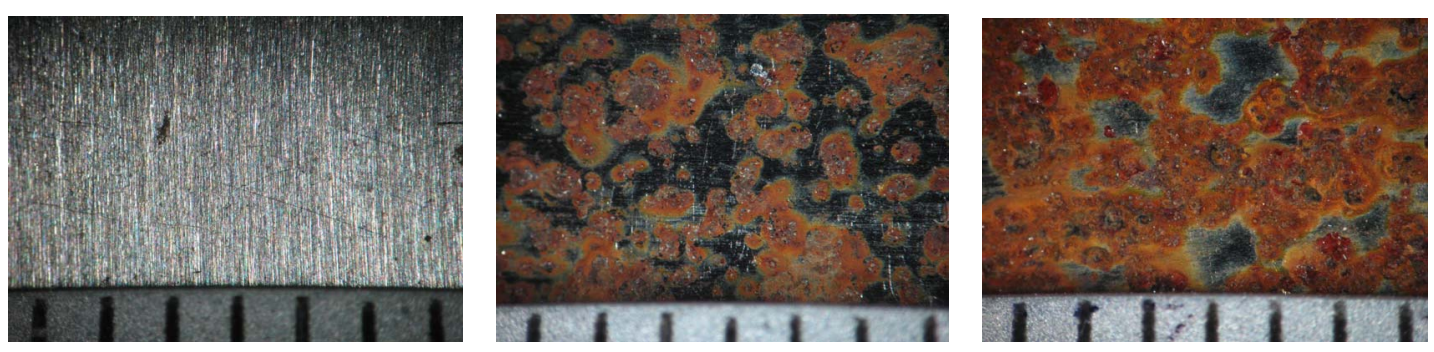

1 day

3 days

7 days

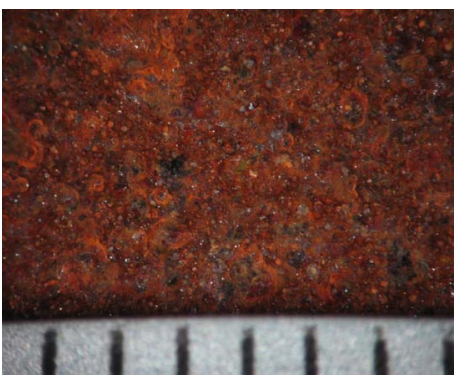

14 days

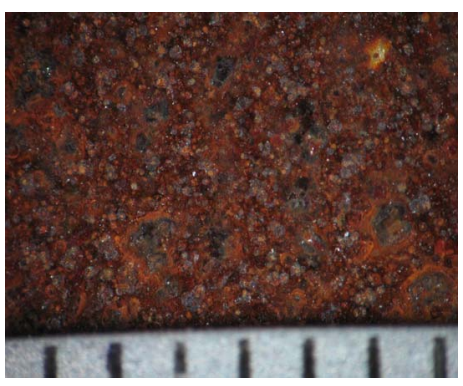

30 days

Figure 4. Surface behavior of tested samples after different exposure time at Hanoi. 


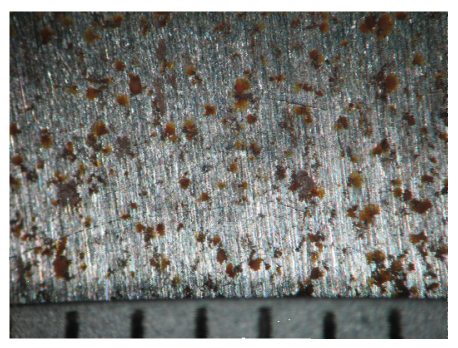

1 day

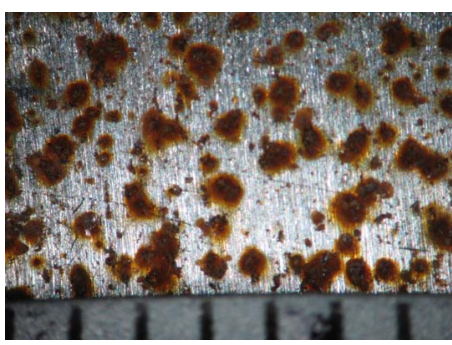

3 days

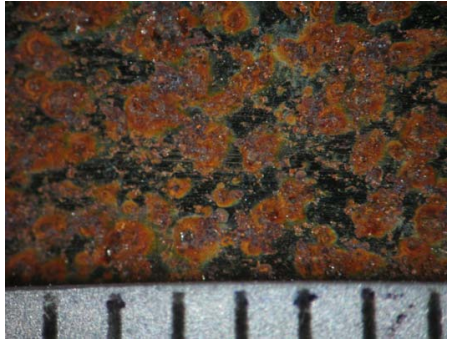

7 days

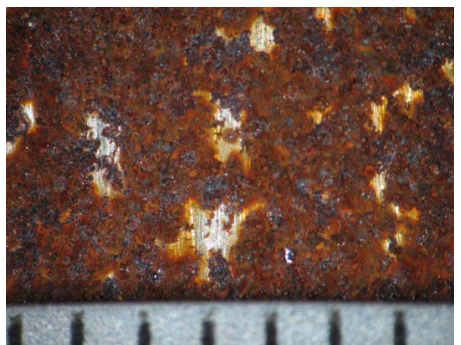

14 days

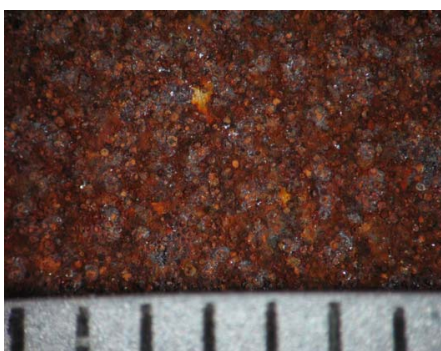

30 days

Figure 5. Surface behavior of tested samples after different exposure time at Donghoi.

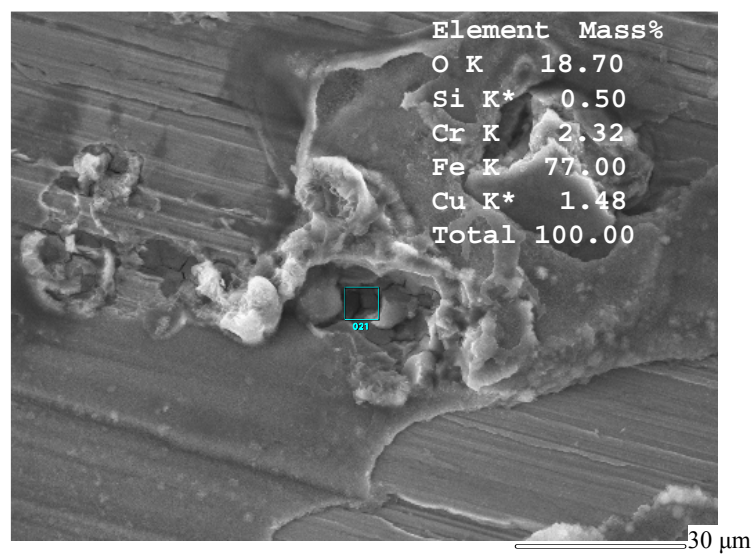

(a)

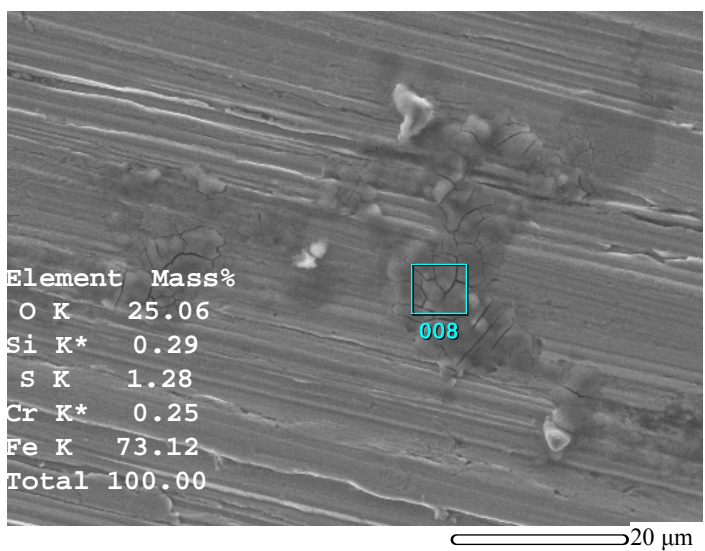

(b)

Figure 6. Chemical composition of CP on samples exposed for 1 day in Donghoi (a) and in Hanoi (b).

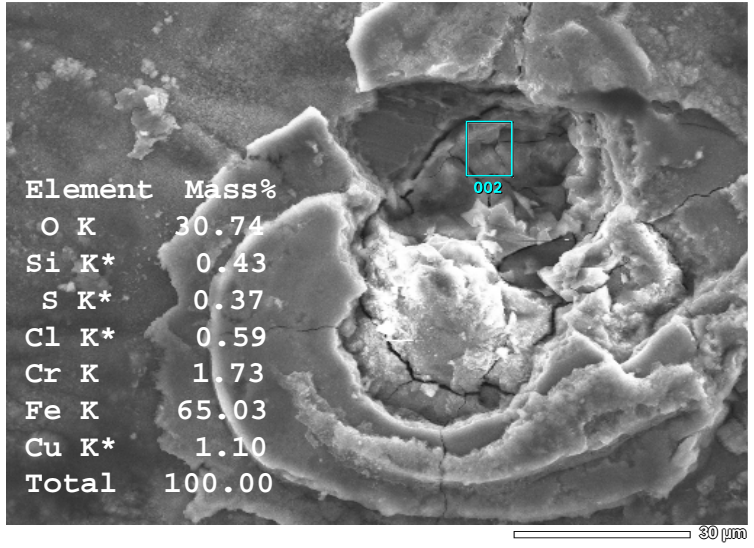

(a)

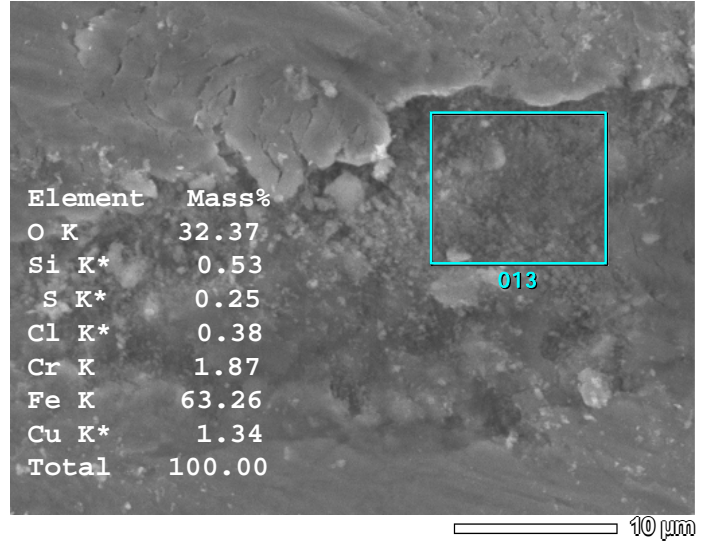

(b)

Figure 7. Chemical composition of CP on samples exposed for 3 days in Donghoi (a) and in Hanoi (b). 


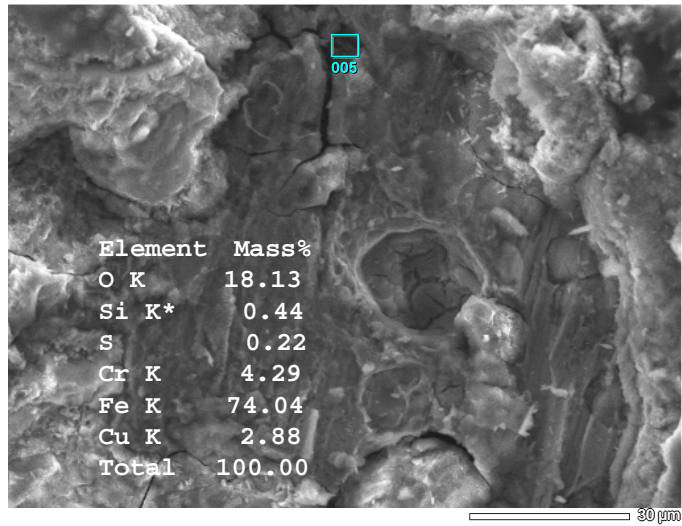

(a)

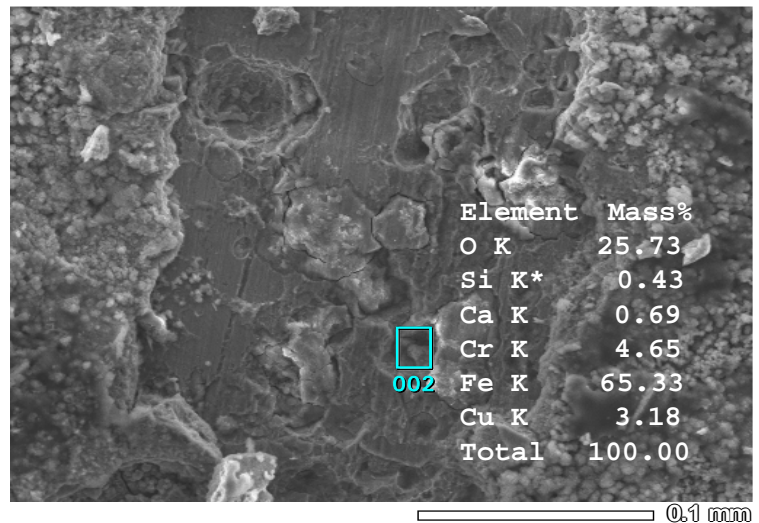

(b)

Figure 8. Chemical composition of corrosion product on samples exposed for 7 days in Donghoi (a) and in Hanoi (b).

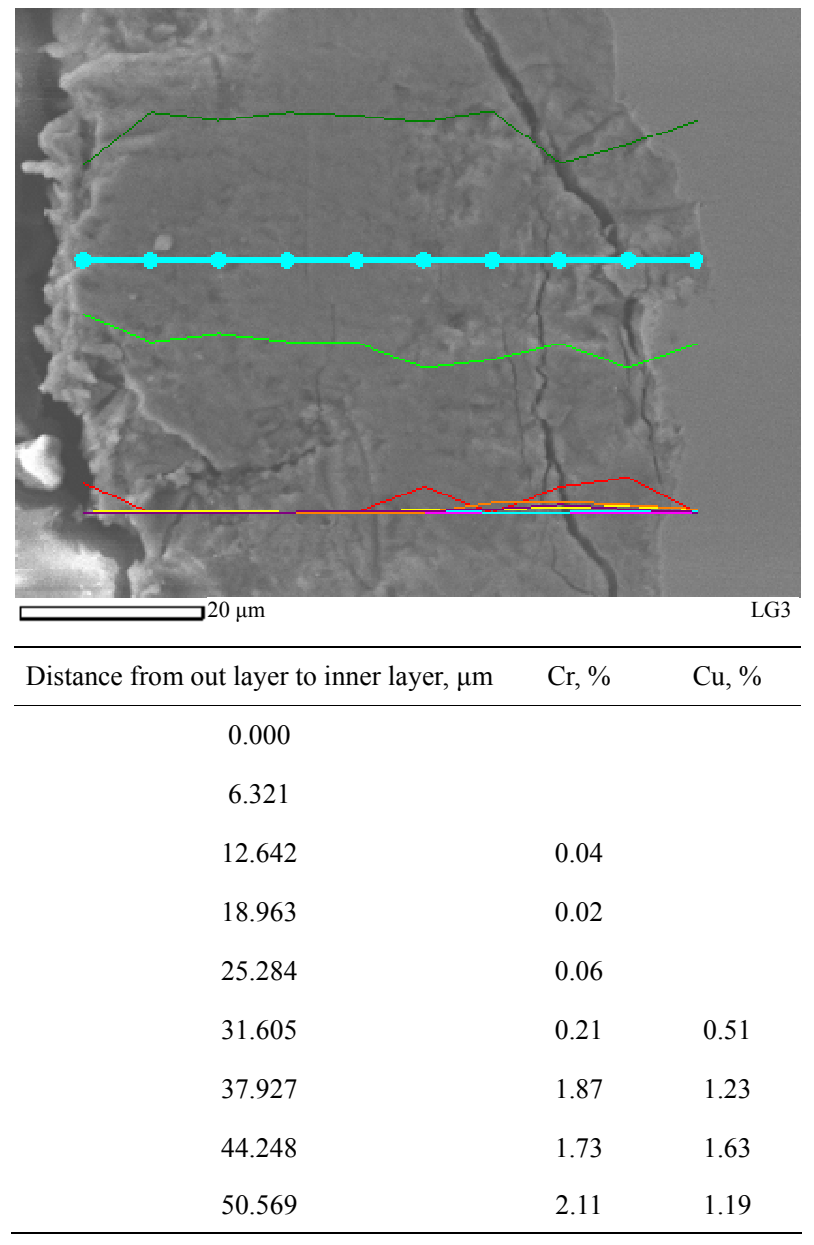

Figure 9. Distribution of $\mathrm{Cr}$ and $\mathrm{Cu}$ from outer layer to inner layer of rust formed on sample exposed to Donghoi site for 30 days.

existence of these alloyed elements.

\subsubsection{The Chemical Compound Composition of Rust} The XRD analysis was done for rust formed in initial stage of exposure, the results showed that the main phases formed in the rust of WS tested in Hanoi and Donghoi are $\alpha$-FeOOH (goethite), $\beta$-FeOOH (akaganeite) and $\gamma$-FeOOH (lepidocrocite). Among them lepidocrocite is dominant and was detected on all tested samples. The $\alpha$-FeOOH phase is considered mainly to contributed to corrosion-protective ability of WS $[1,5,6]$. In addition, the relative insoluble copper hydroxyl-sulfate was also detected in the rust, according to [1] these compounds can precipitate in the pores of rust, thereby improving the barrier effect of CP layer.

The results of Micro Raman analysis of the rust (Figures 10 and 11) showed the presence of different iron hydro-oxides including goethite $\alpha$-FeOOH. This phase appeared sooner on sample exposed at Donghoi than it did at Hanoi, the intensity of peak becomes more clear and sharp with exposure-time. These results are conformable to the XRD-data obtained above.

\subsection{Electro-Chemical Properties of Corrosion Products on Weathering Steel}

In order to determine the electrochemical stability of rust the electro-chemical investigations were performed in $\mathrm{NaCl} 0.1 \mathrm{M}$ solution with electro-chemical cell of three electrodes: $\mathrm{Pt}$ counter, $\mathrm{AgCl}$ reference and working electrodes were sample surface covered with rust after 7,14 and 30 days of exposure.

The polarization curves were measured with potential scan rate of $5 \mathrm{mV} / \mathrm{s}$ (Figure 12). The EIS measurement was conducted at the rest potential with amplitude of 10 $\mathrm{mV}$, the frequency range covered from $10 \mathrm{KHz}$ to 10 $\mathrm{MHz}$. The results are given in the pictures $13 \& 14$. It can be seen that when the exposure time increased the corrosion potential became more positive, thereby the polarization curves shifted towards more positive potential direction. It might be due to the rust layer was more continuous and improved with exposure time. There is 

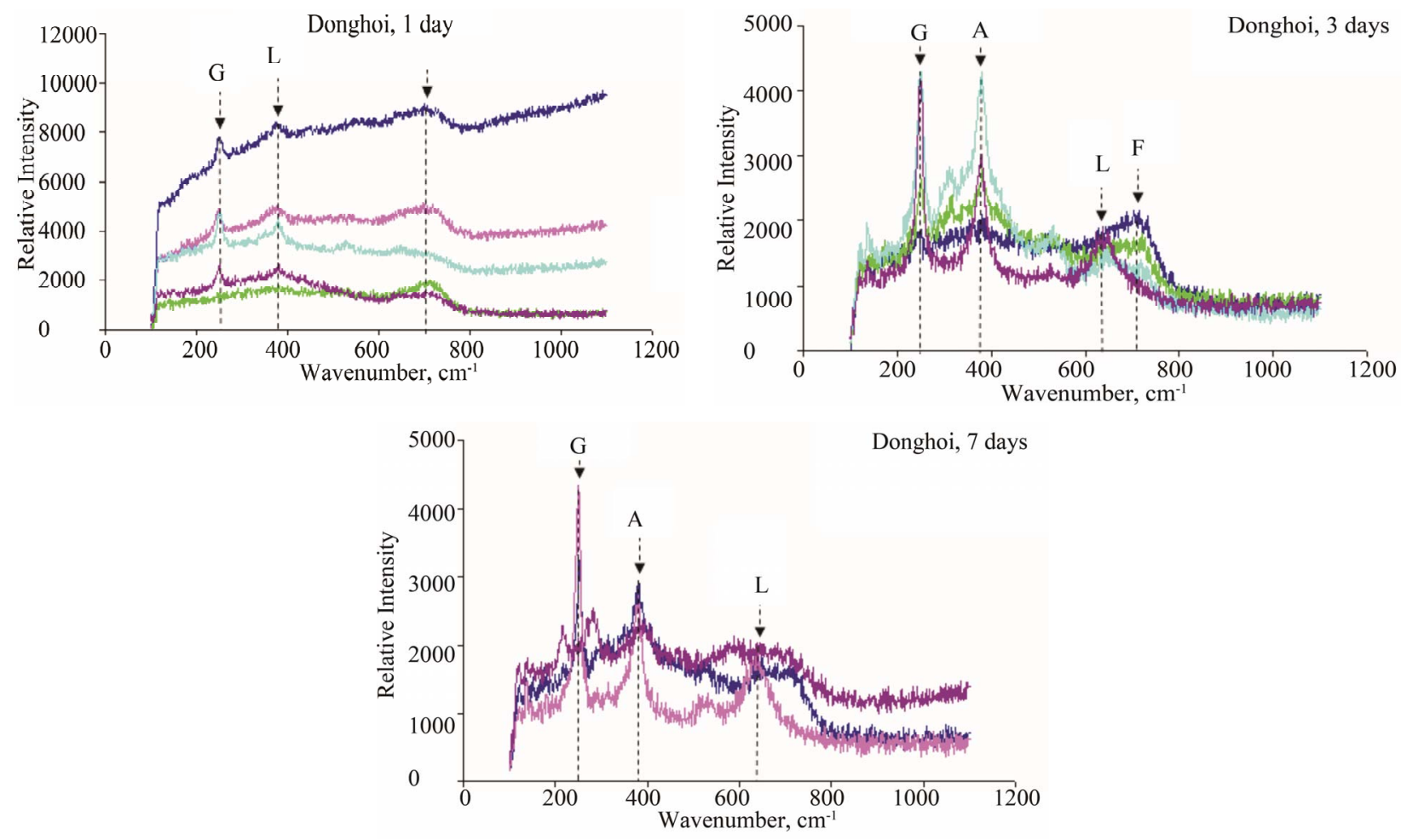

Figure 10. Micro Raman scope of rust formed after different exposure time at Dong Hoi: G: $\alpha$-FeOOH (goethite), A: $\beta$-FeOOH (akaganeite), L: $\gamma$-FeOOH (lepidocrocite), M: $\mathrm{Fe}_{2} \mathrm{O}_{3}$ (maghemite), F: Ferric hydride.
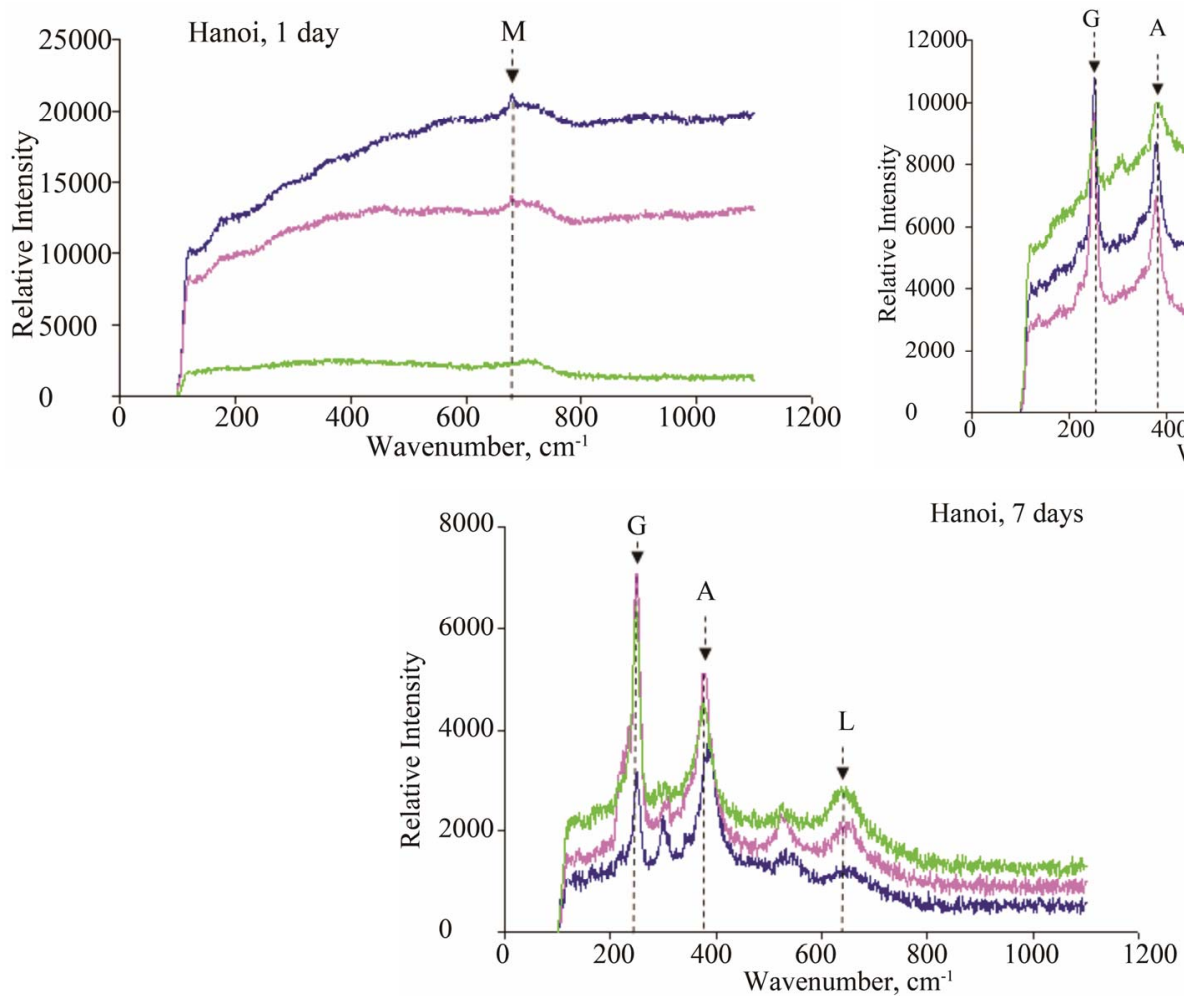

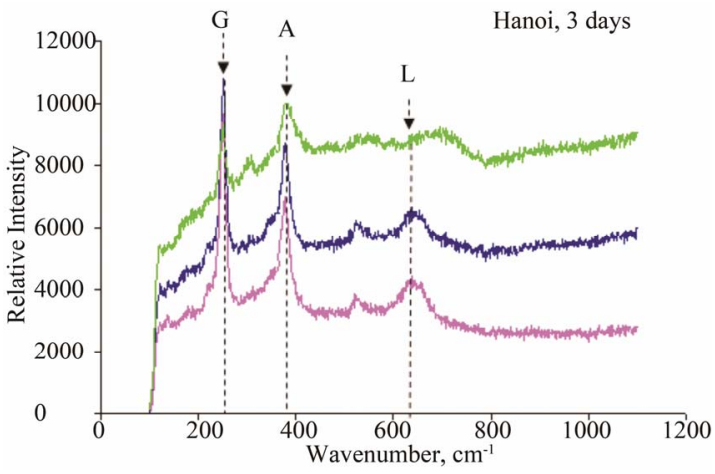

Hanoi, 7 days

Figure 11. Micro Raman scope of rust formed after different exposure time at Hanoi: G: $\alpha$-FeOOH (goethite), A: $\beta$-FeOOH (akaganeite), L: $\gamma$-FeOOH (lepidocrocite), $\mathrm{M}: \mathrm{Fe}_{2} \mathrm{O}_{3}$ (maghemite), F: Ferric hydride. 


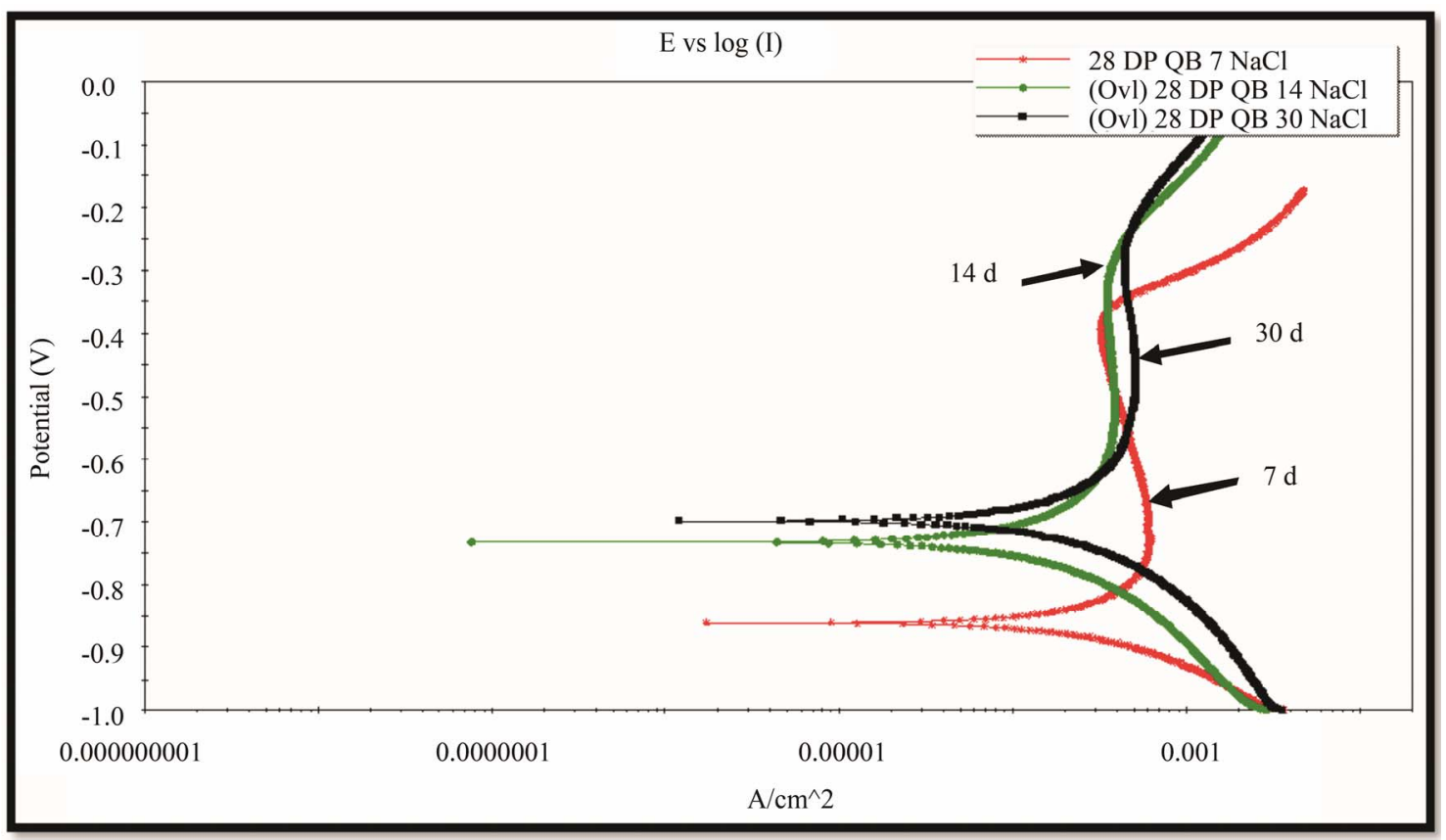

(a) Donghoi

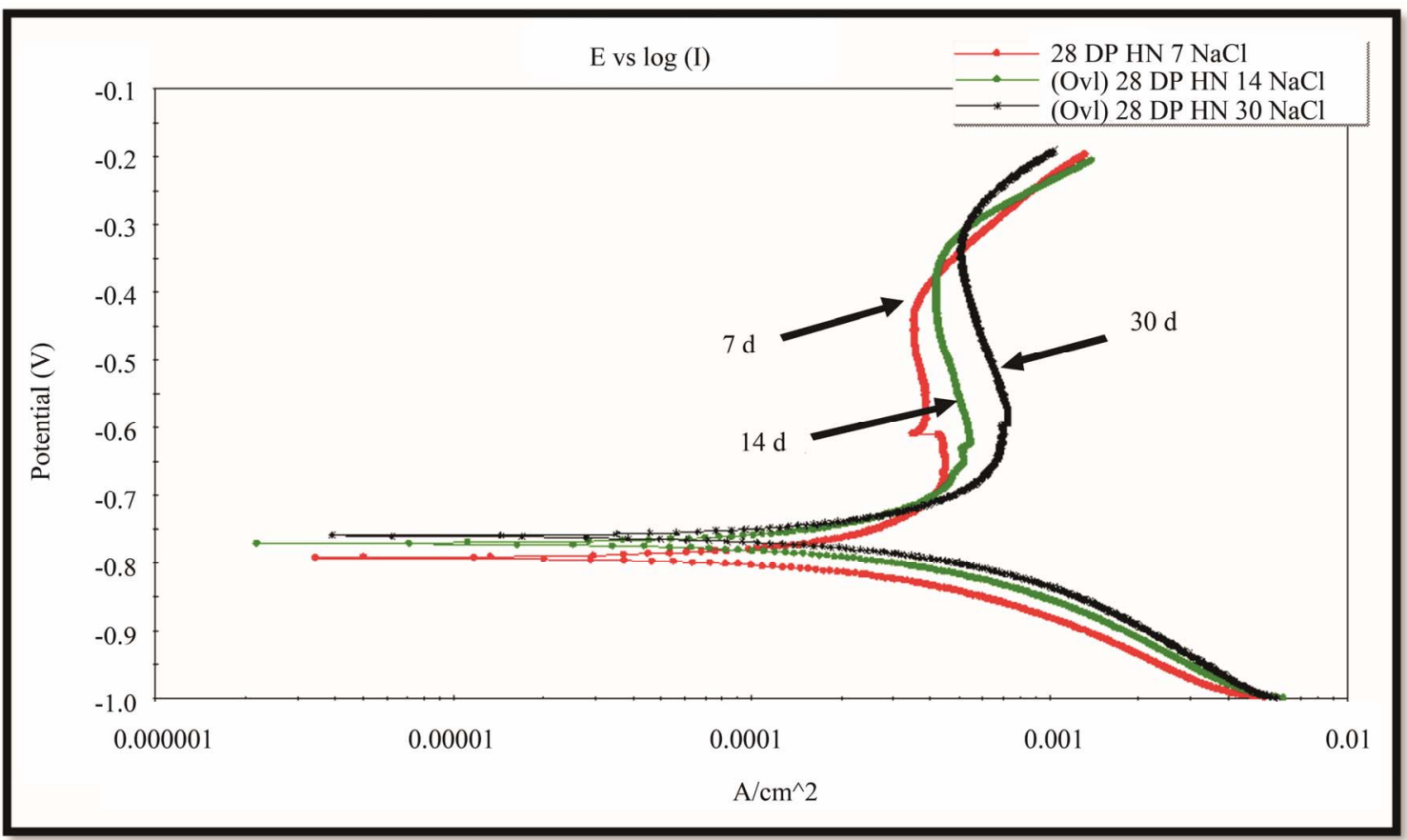

(a) Hanoi

Figure 12. The polarization curves (in NaCl $0.1 \mathrm{M}$ solution, $\mathrm{AgCl}$ reference electrode) of rust layers formed on WS exposed at Donghoi (a) and Hanoi (b) for 7, 14 and 30 days.

one passive part the on anodic branch that expresses more or less protectiveness of rust layer (Figure 12).

The EIS results (Figures 13 and 14) show the enlargement of Nyquist circles with exposure-time that manifest the improvement of rust resistance as well as its protective ability. However it is too early to discuss the results of electrochemical investigation.

\section{Conclusions}

The exposure of WS to outdoor atmosphere of Vietnam was performed. The initial results of testing are as 

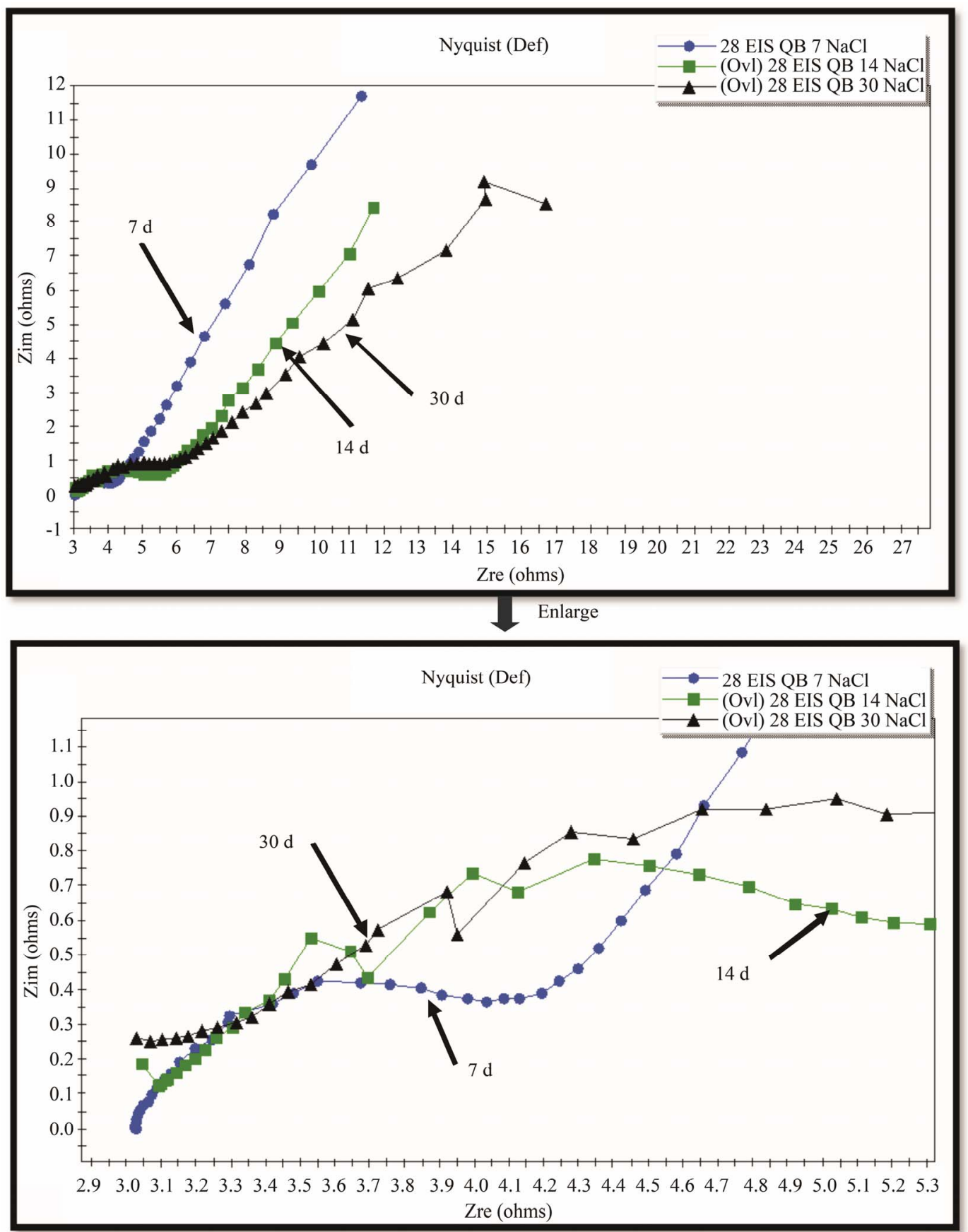

Figure 13. EIS of rust layers formed on WS exposed at Donghoi for 7, 14 and 30 days.

follows:

- The EDX analyses detected the alloyed elements such as $\mathrm{Cr}$ and $\mathrm{Cu}$ in the rust formed in the early stage of exposure ( 1 - 7 days). These elements were found to be rich in the inner layer of rust (closest substrate surface).

- The main compounds of rust formed on WS exposed to Hanoi and Donghoi are $\alpha$-FeOOH (goethite), $\beta$ $\mathrm{FeOOH}$ (akaganeite) and $\gamma$-FeOOH (lepidocrocite).
Among them lepidocrocite is dominant and was detected on all tested samples. The dense $\alpha$-FeOOH phase appeared very soon-just after one day exposure at Donghoi and after three days at Hanoi, in addition, the insoluble copper hydroxyl-sulphates were also detected in the rust. These results were confirmed by XRD and Micro Raman analyses.

- The early appearance of above stable phases perhaps was stimulated by rather high $\mathrm{RH}$ and wet/dry cycling 

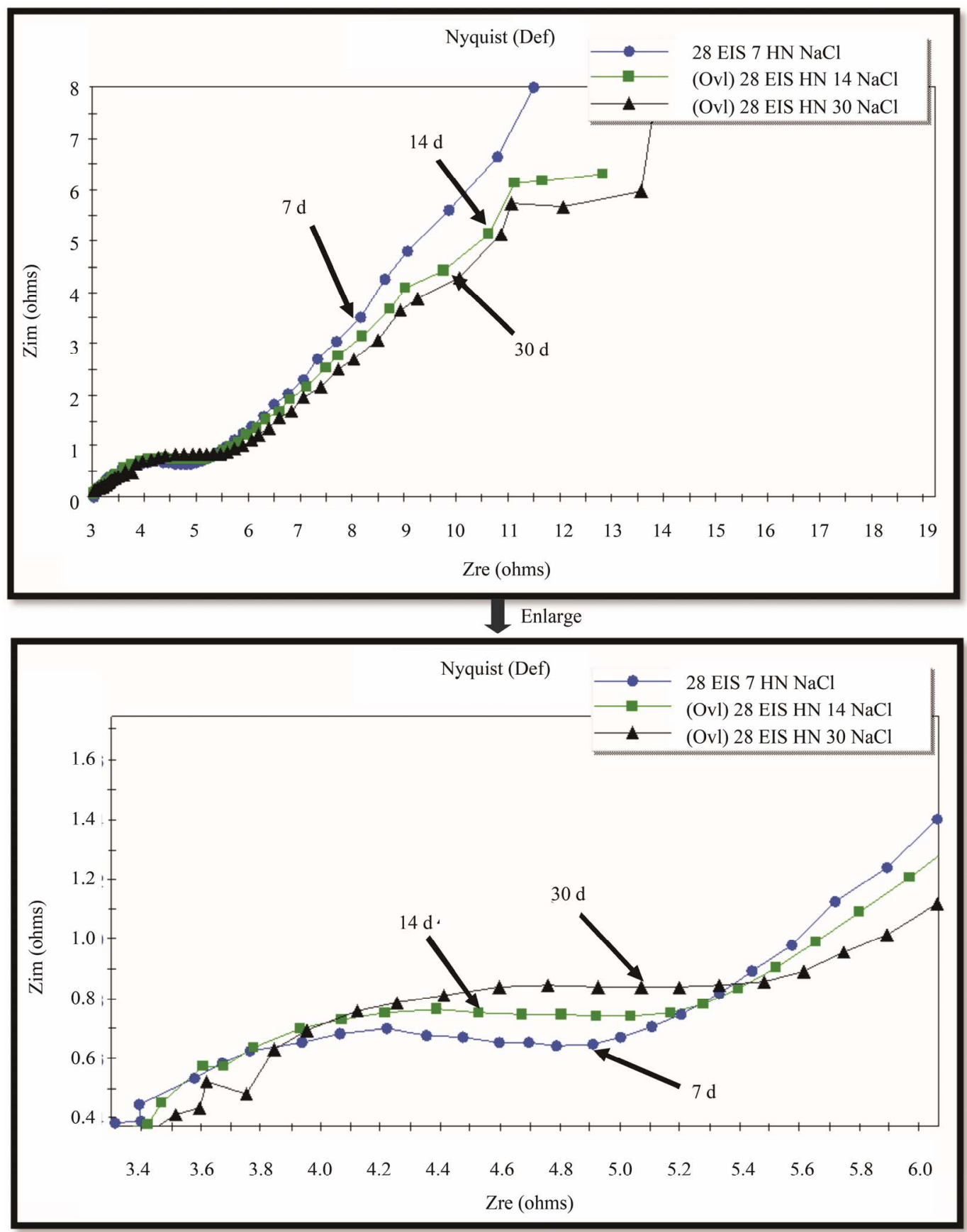

Figure 14. EIS of rust layers formed on WS exposed at Hanoi for 7, 14 and 30 days.

at test sites as soon as initiation of exposure, they contributed to the protective ability of rust that was showed more or less by polarization curves and EIS.

\section{Acknowledgements}

This work has been accomplished with sponsor of Vietnam National Foundation for Science and Technology Development (Nafosted Vietnam), the authors would like to thank this support.

\section{REFERENCES}

[1] C. Leygraf and T. Graedel, "Atmospheric Corrosion," John Wiley and Sons, Inc., Hoboken, 2000.

[2] K. Asami, M. Kikuchi, T. Sato and S. Itoh, "Tem Investigation of Rust on Weathering Steels Exposed for 17 Years," Proceedings of the 15th International Corrosion 
Congress, Granada, 22-27 September 2002, Paper 27.

[3] T. Kamimura, S. Nasu, T. Segi and S. Morimoto, "Corrosion Products Formed on Steel Surfaces Exposed to an Industrial Environment," Proceedings of the 12th AsianPacific Corrosion Control Conference, Osaka, 16-21 September 2003, Paper A-08.

[4] H. Kihira, Y. Ishi and T. Mizoguchi, "Corrosion Protection Mechanism of 3\% Ni Weathering Steel," Proceedings of the 12th Asian-Pacific Corrosion Control Conference, Osaka, 16-21 September 2003, Paper A-11.

[5] H. Kihira, "Colloidal Aspects of Rusting of Weathering Steel," In: H. Oshima and K. Furusawa, Eds., Electrical Phenomena at Interfaces-Fundamentals, Measurements and Applications, Macel Dekker, Inc., New York, 1998, pp. 429-440.

[6] M. Yamashita, H. Konishi, J. Mizukib and H. Uchida, "Nanostructure of Protective Rust Layer on Weathering Steel Exposed for 17 Years Examined by Using Synchrotron Radiation," Proceedings of the 15th International Corrosion Congress, Granada, 22-27 September 2002, Paper 48.
[7] T. Nakayama and T. Ishikawa, "Improvement Mechanism of Resistance to Atmospheric Corrosion of Steels by an Approach of Artificially Synthesized Rusts," Proceedings of the 12th Asian-Pacific Corrosion Control Conference, Osaka, 16-21 September 2003, Paper A-06.

[8] S. Tsuri, A. W. Hassel and M. Stratmann, Electrochemical Behavior of Low Alloy Steels during Atmospheric Corrosion," Proceedings of the 12th Asian-Pacific Corrosion Control Conference, Osaka, 16-21 September 2003, Paper A-05.

[9] M. Kimura and H. Kihira, "Nanoscopic Mechanism of Protective Rust Formation on Weathering Steel Surface," Nippon Steel Report No. 91, Japan, January 2005.

[10] "Metals and Alloys-Procedure for Removal of Corrosion Products from Corrosion Test Specimens," International Standard ISO 8407, Switzerland, 1991.

[11] "Corrosion of Metals and Alloys - Corrosivity of Atmospheres-Measurement of Pollution," International Standard ISO 9225, Switzerland, 1991. 